\title{
"CHAINING". STUDIES OF THE CONCEPTUALIZATION OF GENUINE CONCEPTS OF LINGUISTIC COMMUNICATION IN THE ROOTS OF THE PROTO-LANGUAGE-THESAURUS AND REFLEXES ACROSS LANGUAGE FAMILIES
}

\author{
Fee-Alexandra HAASE \\ United International College (UIC) (Zhuhai. China)* \\ F.hasse1@gmx.de
}

\begin{abstract}
Answering the question "Which notions ('concepts') of languages ('linguistic communication') existed prior to the time of historical age and documented language use?" aiming at the understanding of the phenomenon of natural language use we present in this article concepts of linguistic communication preserved in the hypothetical roots of proto-languages with reflexes in historical words in contemporary languages. Such hypothetical roots are present in natural languages not only limited to a specific language family, but also across the boundaries of the model of the language families. Our analysis of Borean roots referring to linguistic communication shows that the chain building process across language families mostly occurs in the exchange between the Afroasiatic language family, the Eurasiatic language family, and the Sino-Caucasian language family, while the Australic language family and the Amerindian language family are less represented. Building a chain across traditional language families, the roots continue in two to four language families, a fact, which allows us to conclude that many languages on the globe share a set of phonetic sounds as common origin for their thesaurus of linguistic communication independently from their classification in traditional language families.
\end{abstract}

\section{Keywords}

historical linguistics, proto-languages, concepts, linguistic communication, etymology, language families, hypothetical roots, reflexes, prehistoric languages, Borean language family

\footnotetext{
* 2000 Jintong Road, Tangjiawan, Zhuhai, Guangdong Province, China, 519087.
} 
“ENCADENAMIENTO”. ESTUDIOS DE CONCEPTUALIZACIÓN DE CONCEPTOS GENUINOS DE LA COMUNICACIÓN LINGÜÍSTICA EN LAS RAÍCES DEL PROTOLENGUAJE-TESAURO Y LOS REFLEJOS

\section{A TRAVÉS DE LAS FAMILIAS LINGÜÍSTICAS}

\section{Resumen}

Respondiendo a la pregunta “¿Qué nociones ('conceptos') de lenguas ('comunicación lingüística') existían antes de la era histórica y del uso documentado del lenguaje?" con el objetivo de comprender el fenómeno del uso del lenguaje natural presentamos en este artículo el concepto de comunicación lingüística conservada en las raíces hipotéticas de protolenguas con reflejos en palabras históricas de lenguas contemporáneas. Estas raíces hipotéticas están presentes en las lenguas naturales, no solo limitados a una familia lingüística específica, sino también a través de los límites del modelo de las familias lingüísticas. Nuestro análisis de las raíces boreanas que se refieren a la comunicación lingüística muestra que el proceso de construcción encadenado a través de las familias lingüísticas ocurre principalmente en el intercambio entre la familia lingüística afroasiática, la familia lingüística euroasiática y la familia lingüística chino-caucásica, mientras que la familia lingüística australiana y la familia lingüística amerindia están menos representadas. Al construir una cadena a través de las familias de lenguas tradicionales, las raíces continúan en dos de cuatro familias lingüísticas, un hecho que nos permite concluir que muchas lenguas en el mundo comparten un conjunto de sonidos como origen común para su tesauro de comunicación lingüística independientemente de su clasificación en familias lingüísticas tradicionales.

\section{Palabras clave}

lingüística histórica, proto-idiomas, conceptos, comunicación lingüística, etimología, familias lingüísticas, raíces hipotéticas, reflejos, lenguas prehistóricas, familia de lenguas boreanas

\section{Introduction: Theoretical Considerations about Similarities and Relationships of Languages, the 'Comparative Method', and the Concepts of 'Language' and 'Proto- language"}

No doubt: Language changes, it doesn't matter if we look at it like Saussure as a system, a natural rules phenomenon of communication, or as a single expression of a speaker. Since this is the unstable status quo of the phenomenon, we prefer to use the term 'linguistic communication'. The way languages or distinguishable systems of 'linguistic communication' or their selected representations change, can be described by putting them in relation to each other as movements of linguistic change in the 
directions of 'convergence' and 'divergence'. In the case that the lexemic and phonemic contents of a word in a language pair L1 and L2 neither changes in the direction of nonsimilarity ('divergence') nor in the direction of similarity ('convergence'), the chain this contents has built is stable. Historical and - nolens volens- theoretical linguistics and linguistic studies of the de facto existing languages (sociolinguistics) are the fields concerned with similarities observed among traditionally separated forms of 'linguistic communication' like languages or dialects and the derived theories and hypotheses. Here the theory of hypothesis becomes the result from inductive reasoning.

The thesaurus of words or lexemes of languages or 'linguistic communication' also entails words or lexemes, which are concepts of 'linguistic communication'. This applies to natural languages as well as hypothetical languages. In this article we look at the development of genuine linguistic concepts for linguistic communicative activities with a focus on their representations in proto-languages and existing reflexes in natural languages. According to McWhorter's (2016, II) definition in The Story of Human Language, 'language' is an artificial, arbitrary concept: “'Language' is, strictly speaking, an artificial, arbitrary concept." If language is both artificial and arbitrary, we should be able to discover the arbitrary elements and its artificial structure. Genuine linguistic concepts means here that these concepts have a basic hypothetical meaning in the semantic field of linguistic communication. On the contrary, also linguistic concepts exist for the representation of linguistic communication, which are definitely with their basic meaning in the hypothetical language not associated in the semantic field of linguistic communication; an example is the case of the word 'speech', which derived from the concept of 'dispersion' and in later states of natural languages had the reflex of words representing speech. Traditionally, the idea of the separation of known languages into 'language families' of 'language branches' is the dominant idea about languages. The three commonly accepted ways to explain a similarity between words of a language pair are a generic relation (usually as a result of being derivations from a common ancestor), a transfer of a word from one language to another (e.g. loanword), or a purely accidental similarity between two languages. 
(1) Similarity from Generic Relation between Languages

(2) Similarity from Transformational Relation between Languages

(3) Similarity from Accidental Relation between Languages

(4) Similarity from No Relation Between Languages

\subsection{Similarity between a Language Pair L1 and L2 according to Types of Relations}

We can describe these relations as follows:

(1) Generic Relation between Languages

(2) Transformational Relation between Languages

(3) Accidental Relation between Languages

(4) No Relation Between Languages
1. $\mathrm{W}-\mathrm{L} 1=\mathrm{W}-\mathrm{L} 2$ and $\mathrm{W}-\mathrm{L} 3$

2. W-L1 > W-L2 and W-L3

1. $\mathrm{W}-\mathrm{L} 1=\mathrm{W}-\mathrm{L} 2$

2. $W-L 1>W-L 2$

3. $\mathrm{W}-\mathrm{L} 1 \approx \mathrm{W}-\mathrm{L} 2$

4. $\mathrm{W}-\mathrm{L} 1 \geq \mathrm{W}-\mathrm{L} 2$

1. $\mathrm{W}-\mathrm{L} 1=\mathrm{W}-\mathrm{L} 2$ (only phonetically)

2. $\mathrm{W}-\mathrm{L} 1 \approx \mathrm{W}-\mathrm{L} 2$ (only phonetically)

1. $\mathrm{W}-\mathrm{L} 1 \neq \mathrm{W}-\mathrm{L} 2$

\subsection{Description of Types of Relations between a Language Pair L1 and L2 (L3) of a} Word W

The idea of languages as the signs of convergence and belonging to an ethnic group and divergence as a sign of 'otherness' is old. The concept of the genetic development of language in comparison to the development of the human species in a historical process of transfers can be traced to the Bible's story of the Tower of Babel as the unregulated and decadent state of the languages in a society, which fell apart due to the disturbances of the variety of languages in the city, and the three sons of Abraham who represented the founders of three main ethnic groups; the Biblical names Ham and Sem were by linguists used for the description of two of the language families, which covered the related areas, the Hamitic and the Semitic languages. From the traditional perspective of historical linguistics known languages have evolved from former languages and share common ancestral linguistic elements. The terms 'language family' 
or 'language branch' are employed to describe groups of languages with commonly shared linguistic elements. Usually, this relationship is explained by a common heritage. Languages, which emerge from other languages, are commonly grouped as belonging to one language family. In other words: These relations are genuine relationships. Concerning the languages with documentation, which were used in the historical time, we have knowledge about these developments. In contrast to the socio-linguistic idea of "language = belonging" the concept of hypothetical "proto-languages" replaces speculative ideas of the origin of language; actually, it aims also at the replacement of any idea of "origin" of language similarly to the Chomskian approach of "innate universal grammar'. Beyond the historical time we have no documentation of the existence of any languages; historical linguists employ for this lack of knowledge the assumption of hypothetical 'protolanguages', which are considered to be the ancestors of the languages we know today. These proto-languages are considered to be the common ancestor of the historical languages. The assumption of the proto-languages helps the linguists to explain that specific languages have a common heritage and show similarities. Usually, these similarities are shown in the lexicon of the word of these languages and they refer to the three area of linguistics lexicology, semantics, and phonetics, while syntax is usually not related as field of studies of these similarities requiring the comparison of linguistic structures beyond the level of specific words. In most research the historical linguistic research is limited to the area of the lexemes of the lexicon, the semantics, and the phonetics and morphology of languages. The area of the syntax and so the relationship between single words is not subject to historical linguistic studies.
(1) Lexemic Relationships of Historical Languages
Words as Units
(2) Morphological Relationships of Historical Languages
Morphological Elements of Words
(3) Semantic Relationships of Historical Languages
Meaning of Words
(4) Phonetic Relationships of Historical Languages
Soundings of Words 


\subsection{Linguistic Areas of Relationships of Languages}

The idea of the grouping of languages according to families is as old as the idea of the ethnic representation of a group by its language; the grounding idea is that languages "behave" like humans and have a relation to each other similar to the construction of families of humans and other living beings. Similarities between languages can be caused by many effects: On the one hand, the effect of loanwords simply means that one word enters from L1 into L2; this movement occurs in contemporary language contact situations. The genetic relationships is given, when a common heritage is present in two languages. The loanwords are a kind of acquired relationship in only one language, while the genuine relationship with a common heritage is a traditional relationship.

(1) Genuine Relationship between L1 and L2 Loanwords from L 1 into L2

(2) Acquired Relationship between L1 and L1 Common Etymology of Words in both L1 and L2

\subsection{Linguistic Relationships between Language L1 and L2}

A genuine relationship between $L 1$ and $L 2$ are loanwords, which travel from L1 into $L 2$. An acquired relationship between $L 1$ and $L 2$ is a common etymological history of words in both L1 and L2. A common ancestor's history of those languages is presented in the concept of the protolanguages. We must differentiate between the genetic relationship of languages and acquired relationships between languages. Genetic relationships have been established in the past and are immanent in the two languages, which share the similarity. Acquired relationships are relationships, which are ad hocconstructed e.g. by the implementation of loanwords from one to another language.

(1) Diachronic Process of Tradition in Linguistic Communication: Genetic Relationships between Language

(2) Synchronic Event in Linguistic Communication: Acquired Relationships between Languages 
Whereas the acquired relationship between languages means that into an intact L1 a relatively small element of a language L2 is inserted (e.g. a loanword), the genetic relationship between L1 and L2 means that both languages entail a similar element, which cannot be explained as an element, which entered. Comparative linguistic studies compare languages, usually two languages called L1 and L2. This comparison can be done without a reference to the past of these languages, as e.g. in historical linguistic studies, when only the given linguistic data of L1 and L2 are analyzed. Traditionally, the findings of similarities of $L 1$ and $L 2$ are explained as accidental, as a result from the 'migration' of words, or as a result from a common ancestor's history. We assume that we should not ignore in any comparative analysis the overall efforts of historical linguistics and the awareness of historical processes under the aspect of the evaluation of any language. Languages are historical constructs, the most conserving and inheriting storage systems for knowledge we can assume to exist. The differentiation between a 'migrating' loanword and a common ancestor in another language for a word in L1 helps us describing the process of language change in detail. The model of the language families, to which any language L1 usually belongs with the exception of the so-called language isolates, allows to understand the overall phenomenon of similarities between languages. Research, e.g. SIL, is aware of at least the contemporary existing number of natural languages, whereas the more we look at historical languages in the past of historical time the lack of documentation hinders to gain an insight into the qualitative and quantitative knowledge of languages. In prehistoric time the lack of documentation is so grave that linguistic studies are theoretical reconstructions.

\section{State of the Research: Approaches to Language Relationships in Historical Linguistics and in Lexicostatistics}

\subsection{Lexicostatistics and its Methods}

Lexicostatistics as a technique developed by the U.S. linguists Morris Swadesh and Robert Benjamin Lees in the 1940s uses a set of vocabulary in two or more languages, 
which serves as the relevant data for the observation of linguistic similarities of the words between the languages. This method is critically discussed and also partly rejected within the community of historical linguists but has in the $21^{\text {st }}$ century a continuing acceptance and practice supported by computational software applications. The method serves the reconstruction of similarities between languages now extinct and reflexes in historical and documented languages. Within historical linguistics, the concept of the so-called "proto-languages" is a standard concept to explain the common ancestory of historical languages. Inventories of roots have been created by researcher, which indicate the common ancestorial root of the protolanguages for most language families. Usually these inventories are limited to the common proto-language roots for a specific language family. Jackendorff (2016) mentions that the phylogenese of the human species with the hypothetical 'proto-languages' can be compared with the individual development of language learning of humans at an early stage of childhood: "In fact, we do find such 'protolanguage' in two-year-old children, in the beginning efforts of adults learning a foreign language, and in so-called 'pidgins', the systems cobbled together by adult speakers of disparate languages when they need to communicate with each other for trade or other sorts of cooperation. This has led some researchers to propose that the system of 'protolanguage' is still present in modern human brains, hidden under the modern system except when the latter is impaired or not yet developed".

The latest approach for the studies of relationships between languages called 'lexicostatistics' refers to the description of the distances of relations between languages. Lexicostatistics is an approach of comparative linguistics, which is as systematic contrastive study interested in the relatedness of languages, usually language pairs; this is why it is a branch of contrastive linguistics among the methods of comparative linguistics. Usually the approaches of lexicostatistics are based on computational models with samples of words from the languages, which are studied as language pairs. The project E-Linguistics (2016) calculates the genetic proximity between two languages. Let's take the language pair of German and Arabic. Traditionally, Arabic is a language in the Semitic language family and German is a language within the IndoEuropean language family. Even though research was made, which shows the relations 
of words between both languages, no general acceptance between the two language families exists in linguistics and both language families are considered to be separated from each other.

According to E-Linguistics (2016) the genetic proximity between English and German is 30,8 . The genetic proximity between Arabic and German is 75,5 . The genetic proximity between English and Arabic is 77,0. The genetic proximity between Tatar and German is 86,7 . In the project E-Linguistics (2016) the genetic proximity is expressed as a value between 0 (same language) and 100 (biggest possible distance). These values reflect approximately the degree of genetic proximity between 1 and 30 for a pair of 'highly related languages' like English and German. Their protolanguage is a common "ancestor", which came into existence between several centuries and 2000 years. A degree between 30 and 50 is given for 'related languages' with a common protolanguage approx. between 2000 and 4000 years. A degree between 50 and 70 is used for 'remotely related languages' with a common protolanguage approximately between 4000 and 8000 years. A degree between 70 and 80 is used for 'very remotely related languages' with a protolanguage older than 8000 years and also a high chance of interference with chance resemblance. The degree between 80 and 100 is given for language pairs with no recognizable relationship and with a few resemblances measured likely to be due to chance than to common origin. The average genetic proximity of all languages of E-Linguistics is 71,8 . The average statistical expected value is 83.36 with an average standard deviation of 5,03. The expected values and expected standard deviations stated in the pairwise comparisons are specific to these comparisons and reflect their own exposure to chance.

The project E-Linguistics (2016) presents a 'evolutionary tree of languages' generated from 18 words in all languages indicating their genetic distances distinguishing between languages, their sub-families, and families applying a clustering technique in order to generate the tree from the distance matrix by UPGMA (Unweighted Pairwise Group Method with Arithmetic-mean) based on the program MEGA5. (E-Linguistics 2016). The lexicostatistics model of The Global Lexicostatistical Database joined with the Tower of Babel project is based on the comparison of words taken from the Swadish List for the languages, which participate in the analysis. The 
Global Lexicostatistical Database uses GLBD experimental tree-building procedures with the following aims and goals: (1) application of standard comparative-historical procedure to relatively small («level $1 »$ ) databases; (2) attempts to replace potentially subjective historical analysis with "objective» computerized procedures; (3) skipping detailed analysis of individual wordlists and creating a preliminary rough sketch of how one of the highest levels of the GLD could look like in the future. (The Global Lexicostatistical Database 2016) The Global Lexicostatistical Database developed a default tree based on the Swadesh formula and a "objectively generated" tree of phonetic similarity based on complex algorithm with data from all the languages entered into the GLD without traditional etymologically based cognation indexes. (The Global Lexicostatistical Database 2016) George Starostin (2010) in Preliminary Lexicostatistics as a Basis for Language Classification: A New Approach wrote that setting up criteria for judging language relationship comes along with the problem of "the difficulty of differentiating between cognate and contact", which is, of course, not restricted to hypotheses on long-range comparison; it regularly manifests itself in just about every branch of historical linguistics, which has so far been unable to offer it a uniform, objective solution or set of solutions - or, at least, to set up a certain number of strict "rules of conduct" that all historical linguists would agree to obey when dealing with the issue.

Thorough analysis of available data (first and foremost, Indo-European, later augmented by data from other well-studied families) has shown that, in any comparison of two or more related languages, the best way to distinguish between inherited and borrowed lexical strata is to set up two subsystems of phonetic correspondences - one, reflecting the older inherited layer, will inevitably be more complex and difficult to establish, the other one, representing borrowed items, will be more immediately obvious and consist of generally simpler rules." In a recent case of the actualization of the approach of Swadish Dellert \& Buch (2015) in Using Computational Criteria to Extract Large Swadesh Lists for Lexicostatistics are a part of the EVOLAEMP Project. Language Evolution at the University of Tübingen presented 300 top concepts. Among the top 300 concepts are the concepts 'mouth, 'say', 'name', 'call' ('give a name'), 'word', 'language', 'tongue', 'topic', which are related to linguistic communication. 
Another type of lexicostatic approach is the system of reflexes associated with the etyma of Pokorny's List as PIE etyma and IE reflexes edited by Jonathan Slocum in the Linguistics Research Center of the College of Liberal Arts at the University of Texas at Austin. The etymological reflexes of Pokorny's etyma edited by the University of Texas at Austin at the Linguistics Research Center are here word lists derived from Pokorny's list of etyma. Pokorny's list of etyma is comparable to the Swadish List of words most common in all languages not in regard to the actual presentation of a word list, but as a list of commonly shared etyma in the Indo-European languages. Lexicostatistic approaches to linguistics allow seeking for answers about language in a sampling method, which uses data of a limited corpus for statistical calculations concerning the relationships between the languages, which are represented by the data. The two approaches by the project E-Linguistics and The Tower of Babel (The Global Lexicostatistical Database) use such mathematical selection processes for the reconstruction of language families or trees claiming to have more objectivity with their method than a human-made reconstruction like to one of Pokorny.

\subsection{Research Question, Method and Interest of Gaining Knowledge of this Study}

“Which notions ('concepts') of languages ('linguistic communication') existed prior to the time of historical age and documented language use?" is the here challenged research question. For our study it is relevant to have lexical data related to linguistic communication at an earlier stage prior to the emergence of historical languages. The Tower of Babel Project entails lexemes from the major language families of the world. We assume that languages usually not considered to be related languages have actually a common ancestor, we could call this ancestor a proto-protolanguage, which would have existed more than 8000 years ago. We are interested in the Borean roots, which represent the concepts of linguistic communication. Based on the material available at the Tower of Babel Project we demonstrate the range of semantic fields available and covering the semantic field of linguistic communication. We focus here on the Borean roots, which are genuinely covering the semantic field of linguistic communication in contrast to Borean roots or any other linguistic representation for linguistic 
communication, which is a basic conceptual root for linguistic communication, but not a semantic representation of a performance act of linguistic communication. Gell-Mann, Peiros \& Starostin (2016) in Evolution of Human Languages. Testing the "Borean" Hypothesis wrote: "Attempts to arrive at a series of "Proto-World" roots with the aid of so-called "global etymologies" have not been taken seriously by most mainstream linguists, because these "etymologies" frequently rest on surface similarities and depend significantly upon data from insufficiently studied language families. Many particular criticisms of the work done in this field by Merritt Ruhlen, John Bengtson, Vaclav Blazhek, and others have been justified. However, as more and more language families get more detailed comparative-historical treatment, suggested comparanda can be reevaluated and filtered through our up-to-date knowledge of linguistic prehistory."

Gell-Mann, Peiros \& Starostin (2016) wrote about the beginnings of the Borean language-hypothesis and the emerging theory of a "macro-macro-family" called Borean language family: "In fact, already in the late 1980s the corpus of such similarities between two of the largest stocks in Eurasia - Eurasiatic and Dene-Caucasian became so vast that Sergei Starostin had dedicated a special paper attempting to trace regular phonetic correspondences between reconstructed protolanguages of these two macrofamilies. To that corpus he later added comparative data from the Afro-Asiatic and Austric macrofamilies. The provisional "macro-macro-family" that united these four large groups was given the name "Borean" (a term originally used by $\mathrm{H}$. Fleming to designate a somewhat different hypothetical taxon)". Gell-Mann, Peiros \& Starostin (2016) stated that the 'entire area of research' "basically consists of trying to answer three questions: (a) Is "Borean" a reality?; (b) If yes, what are the limits and the internal classification of Borean?; (c) If yes, how old is Borean? The provisional answers, which best suit the accumulated evidence, at this moment are (a) Yes; (b) The four macrofamilies of Eurasia may be marginally closer to each other than to languages in the Americas and Africa, but this model is very easily subject to change as we learn more about the history of the latter taxa; (c) The age of Borean could be anything in the range of $25,000-18,000 \mathrm{BP}$, but not likely to exceed this range (as suggested by various lexicostatistical calculations and overall intuitive assessments)". 
When it comes here to the usage of the term concept, we employ the term for the meaning of a semantic concept of a hypothetical root (see Table 1). In the second part of our study we will demonstrate that from this semantic concept reflexes with the same or a related meaning developed. Among the 20 isolated Borean roots with a semantic reference to linguistic communication we will examine and analyze the roots regarding their existence in five language families. All of the roots isolated here from the database of the Tower of Babel belong at least to two language families. This phenomenon of an either (1) hypothetical root or (2) a reflex being present in at least two language families and thus crossing the borders of established language families we call here "chaining", since the root builds a chain across language families.

\section{Linguistic Concepts for Speech Communication in Roots of Proto-Languages}

The inventory of the Borean language family as theoretical construct, which derived from Starostin's comparative studies in Proto-languages, allows us to see that in the prehistoric time several roots of later Proto-languages as the hypothetical ancestors for the natural languages existed, which referred to the concept of linguistic communication, i.e. speech communication. The Borean language family is a hypothetical linguistic macrofamily including almost all language families except language families in sub-Saharan Africa, New Guinea, Australia, and the Andaman Islands. The hypothetical roots are considered to have the structure consonant, vowel, consonant, vowel: CVCV. The historical linguistic presence in proto-roots of various language families based on the Borean roots of Starostin's Tower of Babel Project etymology for the concept of linguistic communication is as follows:

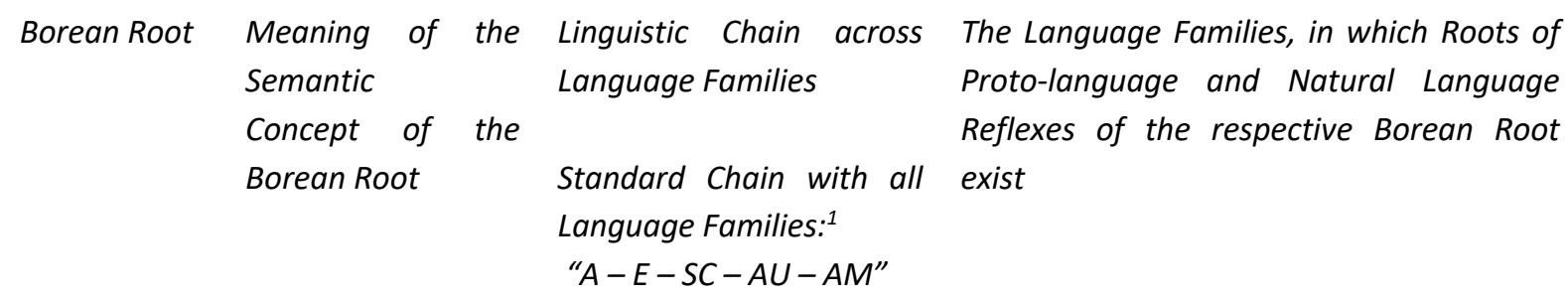

\footnotetext{
${ }^{1}$ Abbreviations for Language Families: A - Afroasiatic Languages; E - Eurasiatic Languages; SC - SinoCaucasian Languages; AU - Australic Languages; AM - Amerindian Languages.
} 


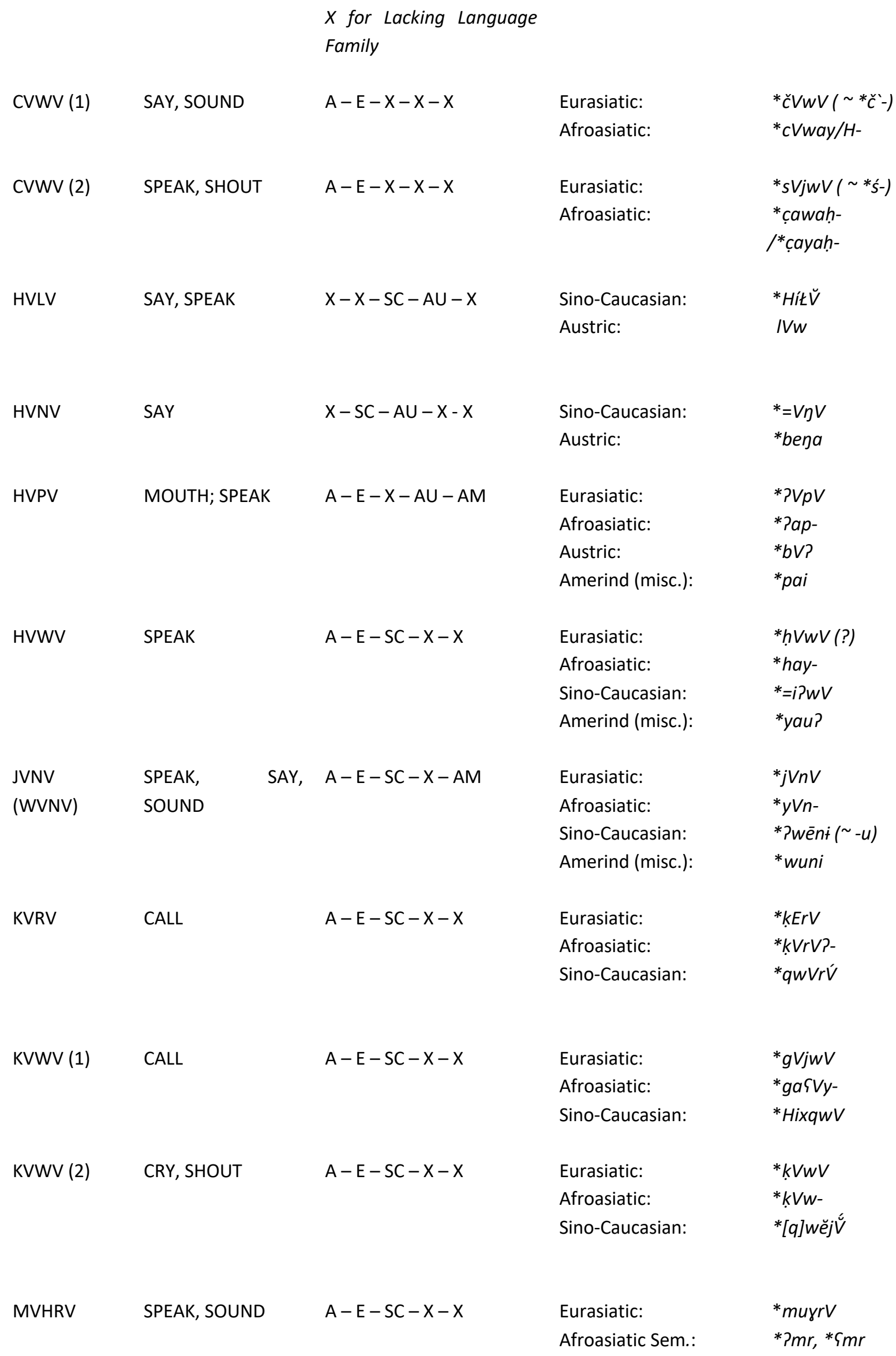




\begin{tabular}{|c|c|c|c|c|}
\hline & & & Sino-Caucasian: & ${ }^{*} m V r H V$ \\
\hline MVLV & SAY, PRAY & $A-E-X-X-A M$ & $\begin{array}{l}\text { Eurasiatic: } \\
\text { Afroasiatic: } \\
\text { Amerind (misc.): }\end{array}$ & $\begin{array}{l}{ }^{*} m \text { VIV } \\
{ }^{*} m \text { VI- } \\
{ }^{*} \text { mali }\end{array}$ \\
\hline NVKV & CALL, SWEAR & $A-X-S C-X-A M$ & $\begin{array}{l}\text { Afroasiatic: } \\
\text { Sino-Caucasian: } \\
\text { Amerind (misc.): }\end{array}$ & $\begin{array}{l}\text { *nug- } \\
\text { *nĕkw̆ } \\
\text { *(a)nik }\end{array}$ \\
\hline PVTV & NAME, CALL & $A-E-X-X-X$ & $\begin{array}{l}\text { Eurasiatic: } \\
\text { Afroasiatic: }\end{array}$ & $\begin{array}{l}* \dot{p} V t V \\
* p V d V d / H-\end{array}$ \\
\hline RVWV & SHOUT & $A-E-S C-A U-X$ & $\begin{array}{l}\text { Eurasiatic IE: } \\
\text { Afroasiatic: } \\
\text { Sino-Caucasian: } \\
\text { Austric: }\end{array}$ & $\begin{array}{l}\text { *rewa- } \\
\text { *rVP-/*rVw- } \\
\text { *?־rH } \\
\text { *rV(w) }\end{array}$ \\
\hline TVHV & SAY & $A-E-X-X-A M$ & $\begin{array}{l}\text { Eurasiatic: } \\
\text { Afroasiatic: } \\
\text { Amerind (misc.): }\end{array}$ & $\begin{array}{l}{ }^{*} t \mathrm{VHV} \\
\text { *ta? }^{-} \\
{ }^{*} t i\end{array}$ \\
\hline TVPV & ASK, CALL & $A-X-S C-X-A M$ & $\begin{array}{l}\text { Afroasiatic: } \\
\text { Sino-Caucasian: } \\
\text { Amerind (misc.): } \\
\text { African (misc.) Bantu: }\end{array}$ & $\begin{array}{l}* d V b- \\
* d V P V \\
* \text { tempa } \\
\text { *-dó(ó)mb- }\end{array}$ \\
\hline WVKV & SAY, CALL & $A-E-S C-X-A M$ & $\begin{array}{l}\text { Eurasiatic: } \\
\text { Afroasiatic Sem.: } \\
\text { Chad.: } \\
\text { Sino-Caucasian: } \\
\text { Amerind (misc.): }\end{array}$ & $\begin{array}{l}{ }^{*} w V k V \\
{ }^{*} w V k H- \\
w V g- \\
{ }^{*}=\dot{V} x \dot{q} V \\
{ }^{*} k o ? e\end{array}$ \\
\hline WVLV & HOWL, CRY & $A-E-S C-X-A M$ & $\begin{array}{l}\text { Eurasiatic: } \\
\text { Afroasiatic: } \\
\text { Sino-Caucasian: } \\
\text { Amerind (misc.): }\end{array}$ & $\begin{array}{l}* w V I V \\
* w V(H) I- \\
*=e ̆ \not ̣ w V ́ \\
* w a l i ' s a y '\end{array}$ \\
\hline WVTV & SPEAK & $A-E-X-X-X$ & $\begin{array}{l}\text { Eurasiatic: } \\
\text { Afroasiatic: }\end{array}$ & $\begin{array}{l}{ }^{*} \text { watV } \\
{ }^{*} \text { wat- }\end{array}$ \\
\hline
\end{tabular}

Table 1. Meanings of the Semantic Concepts of Linguistic Communication of the Borean Roots. The Concepts SAY, CALL, SPEAK, SOUND, PRAY, NAME, ASK, SWEAR, SHOUT, CRY, HOWL in Borean Roots.

Among the 20 Borean roots we examine here, the following distribution can be shown: 
(1) 6 Borean roots are present in 2 language families

(2) 9 Borean roots are present in 3 language families

(3) 5 Borean roots are present in 4 language families
WVTV / HVNV / PVTV / CVWV (1) /

CVWV (2) / HVLV

HVWV / KVRV / KVWV (1) / KVWV (2) / MVHRV / MVLV / NVKV / TVHV / TVPV

HVPV / JVNV (WVNV) / RVWV / WVKV / WVLV

Among the 6 Borean roots, which are present in 2 language families, the distribution is as follows:

$\begin{array}{lll}\text { WVTV } & \text { A-E }-\mathrm{X}-\mathrm{X}-\mathrm{X} & \text { SPEAK } \\ \text { HVNV } & \mathrm{X}-\mathrm{X}-\mathrm{SC}-\mathrm{AU}-\mathrm{X} & \text { SAY } \\ \text { PVTV } & \mathrm{A}-\mathrm{E}-\mathrm{X}-\mathrm{X}-\mathrm{X} & \text { NAME, CALL } \\ \text { CVWV } & \mathrm{A}-\mathrm{E}-\mathrm{X}-\mathrm{X}-\mathrm{X} & \text { SAY, SOUND } \\ \text { CVWV (2) } & \mathrm{A}-\mathrm{E}-\mathrm{X}-\mathrm{X}-\mathrm{X} & \text { SPEAK, SHOUT } \\ \text { HVLV } & \mathrm{X}-\mathrm{X}-\mathrm{SC}-\mathrm{AU}-\mathrm{X} & \text { SAY, SPEAK }\end{array}$

In 4 out of 6 cases, the Afroasiatic and Euroasiatic language families build a chain. In the other 3 cases, the Sino-Caucasian and the Australic language families build a chain.

Among the 9 Borean roots, which are present in 3 language families, the distribution is as follows:

\begin{tabular}{|c|c|c|c|c|c|}
\hline HVWV & $A-$ & $E-S C-$ & $x-$ & $x$ & SPEAK \\
\hline KVRV & $A-$ & $E-S C-$ & $x-$ & $x$ & CALL \\
\hline KVWV (1) & $A-$ & $E-S C-$ & $x-$ & $x$ & CALL \\
\hline KVWV (2) & $A-$ & $E-S C-$ & $x-$ & $x$ & CRY / SHOUT \\
\hline MVHRV & $A-$ & $E-S C-$ & $x-$ & $x$ & SPEAK / SOUND \\
\hline MVLV & $A-$ & $E-X-$ & $x-$ & AM & SAY / PRAY \\
\hline NVKV & $A-$ & $X-S C-$ & $x-$ & AM & CALL / SWEAR \\
\hline VHV & $A-$ & $E-X-$ & $x-$ & AM & SAY \\
\hline TVPV & $A-$ & $X-S C-$ & $x-$ & AM & ASK / CALL \\
\hline
\end{tabular}


In 5 out of 9 cases, the chain of Afroasiatic languages, Eurasiatic languages, and Sino-Caucaisan languages exists, in 4 other cases the Afroasiatic language family is also present and connected with the Amerindian language family plus in two cases the Eurasiatic language family or in two other cases the Sino-Caucasian language family. Among the 5 Borean roots, which are present in 4 language families, the distribution is as follows:

$\begin{array}{lll}\text { HVPV } & A-E-X-A U-A M & \text { MOUTH / SPEAK } \\ \text { JVNV (WVNV) } & A-E-S C-X-A M & \text { SPEAK/SAY / SOUND } \\ \text { RVWV } & A-E-S C-A U-X & \text { SHOUT } \\ \text { WVKV } & A-E-S C-X-A M & \text { SAY / CALL } \\ \text { WVLV } & A-E-S C-X-A M & \text { HOWL / CRY }\end{array}$

As we can see, in 4 of 5 cases found the Australic language family is missing and in one case the Amerindian language family. Independently from the actual number of chain building elements, we can say that in the majority of elements the Afroasiatic language family is present, followed by the Sino-Caucasian and the Eurasiatic language family. The distribution of the presence in the chains above is as follows:

Afroasiatic Language Family
Sino-Caucasian Language Family
Eurasiatic Language Family
Amerindian Language Family
Australic Language Family

Besides the Borean concepts, which refer to linguistic communication, we have also Borean concepts, which have no semantic meanings with reference to linguistic communication, but alter in the course of the hypothetical language state and the historical language state to words with conceptual meanings related to linguistic communication. The Borean roots above are roots, which semantically represent meanings related to linguistic communication.

\author{
Represented in: 18 out of 20 cases \\ Represented in: 17 out of 20 cases \\ Represented in: 16 out of 20 cases \\ Represented in: 8 out of 20 cases \\ Represented in: 4 out of 20 cases
}




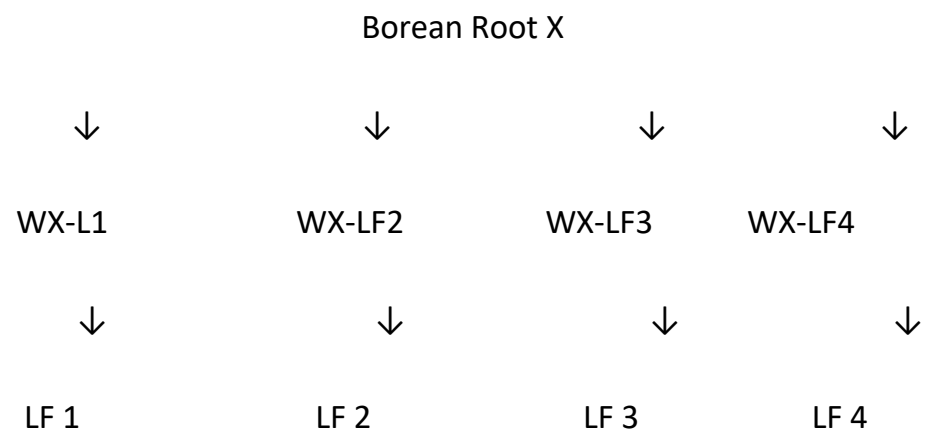

\subsection{Model of Borean Roots entering Natural Languages}

The semantic fields for linguistic communication comprise simple and complex actions of speaking. Simple actions of speaking are associated to the following roots:

$\begin{array}{ll}\text { WVTV } & \text { SPEAK } \\ \text { HVNV } & \text { SAY } \\ \text { HVLV } & \text { SAY, SPEAK } \\ \text { HVWV } & \text { SPEAK } \\ \text { TVHV } & \text { SAY } \\ \text { MVHRV } & \text { SPEAK / SOUND } \\ \text { HVPV } & \text { MOUTH / SPEAK } \\ \text { JVNV (WVNV) } & \text { SPEAK / SAY / SOUND } \\ \text { WVKV } & \text { SAY / CALL }\end{array}$

Complex actions of speaking, which have an additional component specifying the linguistic action, are as follows:

$\begin{array}{ll}\text { PVTV } & \text { NAME, CALL } \\ \text { CVWV } & \text { SAY, SOUND } \\ \text { CVWV (2) } & \text { SPEAK, SHOUT } \\ \text { KVRV } & \text { CALL } \\ \text { KVWV (1) } & \text { CALL } \\ \text { KVWV (2) } & \text { CRY / SHOUT } \\ \text { MVLV } & \text { SAY / PRAY } \\ \text { NVKV } & \text { CALL / SWEAR }\end{array}$




$\begin{array}{ll}\text { TVPV } & \text { ASK / CALL } \\ \text { RVWV } & \text { SHOUT } \\ \text { WVLV } & \text { HOWL / CRY }\end{array}$

We see that the first set of linguistic concepts is related to a simple performance of language use, while the second set specifies the linguistic activities. In the following section we will examine if and how the conceptual meaning associated to the Borean roots changes in the reflexes of the historical languages.

\section{Meanings of the Semantic Concepts of Linguistic Communication of the Borean Roots}

\subsection{Inventory of Linguistic Concepts of Linguistic Communication}

Borean and hypothetical roots can change completely their meaning and loose or modify their basic meaning of linguistic communication, when they are applied in natural languages. In this section we look at the reflexes of the concepts associated with the Borean roots in natural languages.

\subsection{Concepts with Eurasiac Roots}

4.1.1 Concepts with Eurasiac Roots and with Indo-European Representations

a) WVKV with the conceptual meanings $S A Y, C A L L$ and reflexion in $A-E-S C-X-A M$

Eurasiatic ${ }^{*} w V k V$, Afroasiatic Semitic ${ }^{*} w V k H-$ 'clamour' and 'boast', SinoCaucasian ${ }^{*}=\dot{V} x \dot{q} V$, and Amerind *kope 'say' refer to the Borean root WVKV. Eurasiatic ${ }^{*} w V k V$ has the meanings 'say' and 'call'. Related are Indo-European *wek ${ }^{w}$ - and *(e)wegwhe-, Altaic *oki, Uralic *wakV, and Eskimo-Aleut *uqa-. Proto-Indo-European *wekw ${ }^{w}$ has the meanings 'say' and 'tell'. Related are Tokharian A wak, B wek for 'voice' 
and 'noise', Old Indian vakti for 'speak', 'say', 'tell' and vácas- for 'speech', 'voice', 'word', and vắc- for 'speech', 'voice', 'word'. Avestan vačah for 'speech' and 'word', vāx$s$ for 'voice', 'speech', and 'word', Armenian gočem for 'cry', 'call', 'invite', 'name', Old Greek épos for 'word', 'song', 'epic poem', and Slavic *vetjb, Germanic *wax-n-ia-, *wax-t-a-, *wōx-, *wix-t-i-, *wáx-a-/*wag-á-, Latin vox for 'sound', 'echo', 'voice', 'word', 'speech', and 'sentence' as well as vocare for 'name' and 'call' and Celtic Middle Irish fūaimm for 'noise' refer to it. Proto-Sino-Caucasian *=V́x $\dot{q} V$ has the meaning 'word' with the reflexes of North Caucasian ${ }^{*} \dot{q} l a-$, Sino-Tibetan ${ }^{*} k(h) a$, and Yenisseian ${ }^{*} q a \ddot{P} G$. WVKV becomes in some historical languages the additional meaning 'tell', while 'say' and 'call' stay stable meanings.

b) CVWV with the conceptual meanings $S A Y$, SOUND and reflexion in $A-E-X-X-X$

CVWV refers to Eurasiatic ${ }^{*} \check{C} V w V\left(\sim{ }^{*} \check{c}-\right)$ and Afroasiatic ${ }^{*} c V w a y / H$-.Eurasiatic *sVjwV has the meanings 'speak' and 'shout'. Indo-European *suei-, Altaic *sa[jb]o, Uralic *soje, and Kartvelian *çw- refer to it. Proto-Afro-Asiatic *çawah-/ and *çayahhave the meanings 'shout' and 'ask'. Semitic *ș $W / y V h$ - 'shout' and 'call', Western Chadic * çVwVh- and *c̣VyVḥ- 'ask', East Chadic *say-, High East Cushitic * çeh- 'call', and South Cushitic *ce?- for 'shout' refer to the Proto-Adro-Asiatic roots. CVWV keeps 'shout' in the historical languages and as additional meanings 'ask' and 'call.'

c) MVLV with the conceptual meanings SAY, PRAY and reflexion in $A-E-X-X-A M$

Eurasiatic * $m V I V$, Afroasiatic * $m V I-$, Amerind *mali ('talk'), and Eurasiatic * $m V I V$ refer to the root MVLV with the meaning 'pray'. Reflexes are Indo-European *meldhand *mleu-, Altaic *mióle, Uralic *mele, and Kartvelian *madl-. Proto-Indo-European *meldh- has the meanings 'ask' and 'beg'. Reflexes are Hittite malta- (mald-) for 'vow',

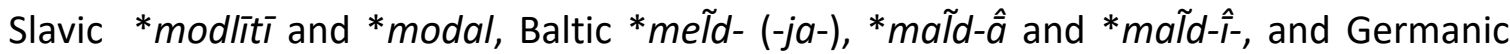
${ }^{*}$ mild-e-e-, *mild-o-o-, *mild-ō(n-). Proto-Afro-Asiatic *mVI- has the meanings 'speak' and 'call' with representations in Semitic * $m$ VI- 'speak', Berber * $m$ VI- for 'say', 'indicate', 
'shout', 'call', and Central Chadic *myal- 'call'. MVLV keeps in historical languages the meaning 'say' and as additional meanings 'ask', 'beg', 'vow', 'call', and 'indicate'.

d) TVHV with the conceptual meaning SAY and reflexion in A $-E-X-X-A M$

Eurasiatic * $t V H V$, Afroasiatic *ta?-, Amerind * $t i$ 'say', and Eurasiatic * $t V H V$ refer to the Borean root TVHV with the meaning 'say'. Indo-European *dé-, Altaic *té, Kartvelian *txow-, Dravidian *Tev- refer to it. Proto-Indo-European *d(h)e-e with the meaning 'say'

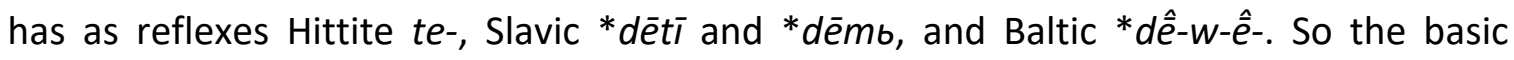
conceptual meaning stays within the historical languages.

f) KVRV with the conceptual meaning CALL and reflexion in $A-E-S C-X-X$

Eurasiatic *kErV, Afroasiatic *kVrVP-, and Sino-Caucasian * $q w V r V$ refer to the root KVRV. KURV has reflexes in Eurasiatic * $k E r V$ with the meaning 'call'. It is reflected in the Indo-European *kar[a]- and *kr[ā]-. Altaic *k'ēro, Uralic *kerä, Kartvelian *keir- and *kil-, Dravidian *kēr- and the Proto-Afro-Asiatic *fiwah- with the meanings 'blow', 'smell', 'breathe' and Semitic * $p V w V h$ - and *pVhhh- for 'breathe', 'blow', 'spread (smell)', Western Chadic *fayVh- 'blow' and 'smell', Central Chadic * Pi-fiyaH-'smell', East Chadic *pwaH- and *pVwaH- 'blow', Central Cushitic (Agaw) *fi/ahw-'blow' and 'breathe', 'take rest', 'breath', 'soul', South Cushitic *fah- 'blow'. Proto-Sino-Caucasian *qwVrV́ has the meaning 'ask' with representations in North Caucasian ${ }^{*} H r e q w \breve{A}(r)$, Yenisseian ${ }^{*} t-V \chi V$, and Burushaski *-yárVs-. The Borean root extends to 'blow', 'smell', 'breathe', and 'ask'.

g) KVWV (1) with the conceptual meanings CALL and reflexion in $A-E-S C-X-X$

Eurasiatic * $g V j w V$, Afroasiatic *gaৎVy-, Sino-Caucasian *HixqwV refer to the Borean root KVWV. The Proto-Indo-European roots ${ }^{*} g^{\prime} h a w \partial-$ and ${ }^{*} g^{\prime} h w \bar{V}$ - have the meaning 'call'. Tokharian B $k w \bar{a}-$ means 'call out to' and 'invite'. Old Indian hávate means 'call' and 'summon'. Avestan zavaiti means '(he) calls', zavana- means 'call' and 'invocation', Armenian zaunem 'consecrate' and n-zovkh 'curse', Slavic *zovō, *zъvātī, 
*zovъ 'call', Baltic *̌̌aw-ê-- 'cast a spell' Celtic Old Irish guth 'voice', Proto-ChukcheeKamchatkan *'ayjiv- is represented in Proto-Chukchee-Koryak *ayzib- and Proto-Itelmen *hela- $\eta$. Proto-Afro-Asiatic *gay(H)- is represented in Semitic *gVG/PVy- 'roar' and 'scream', Egyptian of the Pyramide Texts d_wy (pyr) 'call', Western Chadic *gay/H- 'tell' and 'say', Central Chadic *gay- 'call', East Chadic Kwan Pógé, Sumray ?wògà, Tumak wàg, Sokoro yēg-for 'call', Warazi (Dullay) Tsamai gaha 'say', and Omotic *gay- 'say'. Proto-Sino-Caucasian *HixqwV has the meaning 'name' and reflexes in Yenisseian * PiG ( $\sim$ * Pix) and Burushaski *jek. The meaning of the Borean root stays and additional meanings added are 'call', 'invite', 'summon', 'consecrate', 'curse', 'roar', 'scream', and 'name'.

h) KVWV (2) with the conceptual meanings CRY, SHOUT and reflexion in A - E - SC - X $X$

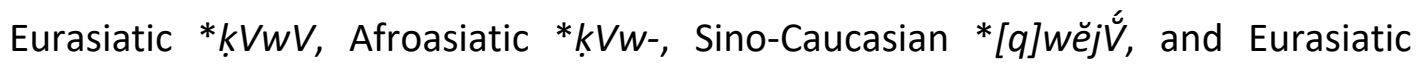
${ }^{*} k V W V$ refer to the root KVWV. Indo-European *kewa- for 'shout' is represented in the reflexes of Altaic *kijube, Kartvelian * $\dot{q} i w$-, Dravidian *kav-. Reflexes are Old Indian káuti, Old Greek kōküō for 'whine', Slavic *kovấtī, and Germanic *xiuw-il-ō- and the Proto-Germanic root *xūwilōn- for 'howl' with the reflexes of Danish hyle, Middle English hūlen, English howl, Middle Dutch hūlen, Dutch huilen, Middle Low German hūlen, Old High German hūlōn, Middle High German hiuwelen and German heulen. The Borean root extends to 'whine' and 'howl' in the historical languages.

i) WVTV with the conceptual meaning SPEAK and reflexion in $A-E-X-X-X$

Eurasiatic * watV and Afroasiatic * wat- refer to the Borean root WVTV. The Borean root is represented in Eurasiatic *watV with the meaning 'speak'. Indo-European *wedis represented in Altaic *ót 'e ( $\sim-t-)$, Uralic *wa[t]V for 'word', Dravidian *vadar_- (+ SDr *ōd-) for 'read' and 'recite', and Eskimo-Aleut *atzs and *atRis-. Proto-Indo-European *wod- with the meanings 'speak', 'sing', and 'scold' has reflexes in Hittite uttar for 'word', Tokharian A wätk- and B watk- for 'order', Old Indian vádati for 'speak', 'say', 
'utter', 'tell' and vāda- for 'speaking of or about' and 'speech', 'discourse', and 'talk'. Old Greek hüdéō means 'sing about' and audẳ means 'human voice', 'sound', and 'speech'. Other reflexes are Slavic *vádā and *vádītī and Baltic *wad-in̂-and *wad-î̀-. Proto-AfroAsiatic *wat- (?) has the meanings 'call' and 'speak'. Related are Western Chadic *watfor 'call', East Chadic *waat-, and Omotic *w/yat- 'say' and 'speak'. The Borean root extends in the historical languages to 'read', 'recite', 'sing', 'scold', 'order', 'utter', 'tell', and 'call'.

j) CVWV (1) with the conceptual meanings SPEAK, SHOUT and reflexion in A-E - X $-X-$ $\mathrm{X}$

Eurasiatic *sVjwV and Afroasiatic *çawah- and *cayah- refer to the Boean root CVWV. Eurasiatic *sVjwV has the meanings 'speak' and 'shout'. Indo-European *sueiequal to Pokorny's etymon 1040-41 represented in the reflex suadere ('urge' and 'advice') has its reflexes in Altaic *sa[jb]o, Uralic *soje, and Kartvelian *çw-. IndoEuropean *suei- refers to Pokorny's etymon suăd- for 'sweet' and 'enjoy something'. Other related Latin words are dissuadere for 'dissuade' and persuadere for 'persuade' and suasio for 'suasion' and 'persuasiveness'. The Proto-Afro-Asiatic roots *çawah- and * çayah- with the meanings 'shout' and 'ask' are represented in Semitic *șW/yVh-for 'shout' and 'call', Western Chadic *çVwVh- and *çVyVh- for 'ask', East Chadic *say- (?), High East Cushitic * çeh-for 'call', and South Cushitic *ce?- for 'shout'. The Borean root is in the historical languages extended to 'urge', 'advice', 'ask', and 'call'.

k) CVWV (2) with the conceptual meanings SAY, SOUND and reflexion in $A-E-X-X-X$

Eurasiatic * ${ }^{c} V w V$, Afroasiatic ${ }^{*} c V w a y / H-$, and Eurasiatic *čVwV with Altaic *čá ${ }^{*} b u$ and Kartvelian [*caw-] refer to the Borean root CVWV. Indo-European *stewə- and *(s)teubh-) as well as Proto-Indo-European *steu- have the meanings 'commend' and 'affirm'. Reflexes are Hittite isduwa- 'become clear', Old Indian stáuti and stávate for 'praise', Avestan staoiti for 'praise', Old Greek stêutai for 'announce in a solemn way', 'promise', 'theraten', and 'claim'. Proto-Afro-Asiatic * $c V w a y / H$ - with the meanings 
'speak' and 'shout' is represented in the Semitic *sVH- 'cry (of pain)', Egyptian swhy for 'shout', Western Chadic *s/cay-for 'say' and 'speech', Central Chadic *suw-for 'shout', 'cry', and 'answer', East Chadic *sway for 'cry', 'say', and 'tell', and South Cushitic *ce?for 'shout'. The Borean root is in the historical languages extended to 'commend', 'affirm', 'become clear', 'praise', 'announce in a solemn way', 'promise', 'threaten', 'claim', 'speak', 'shout', 'cry', and 'tell'.

I) HVWV with the conceptual meanings SPEAK and reflexion in $\mathrm{A}-\mathrm{E}-\mathrm{SC}-\mathrm{X}-\mathrm{X}$

Eurasiatic * $h V w V($ ?), Afroasiatic *hay-, Sino-Caucasian EC * $=i ? w V$, and Amerind *yau? for 'mouth' and 'say' refer to the Borean root HVWV. Eurasiatic *hVwV (?) has the meaning 'speak'. Related roots are Indo-European *Heu- (with Pokorny's etyma 76-77), Chukchee-Kamchatkan *iv- and *š-jiv- as well as Proto-Chukchee-Kamchatkan *'ivu-, Proto-Chukchee-Koryak *ib- and *š-zib-, and Proto-Itelmen *'ən-'izu-. The etyma 76-77 au- and aued-have the meaning 'speak'. In the Indo-European languages it has reflexes in Old High German farwazan for 'deny', Latin melodia for 'melody' and oda/ode for 'ode', 'song', 'strophe', Homeric Greek aeídô for 'sing' and Greek ádein for 'sing' as well as aude for 'voice' and ôdê/aoidê for 'ode', 'song', and 'strophe' and in Indic Pali theravada for 'doctrine of the elders'. The Borean root is in the historical languages extended to 'deny'.

m) WVLV with the conceptual meanings HOWL, CRY and reflexion in $A-E-S C-X-A M$

Eurasiatic * $w V I V$, Afroasiatic * $w V(H) I-$ for 'cry', 'sound', and 'speak', SinoCaucasian * $=\check{x} \chi \underline{W} w \bar{V}$, and Amerind *wali for 'say' refer to the Borean root WVLV. The Eurasiatic root * $W V I V$ has the meanings 'howl' and 'cry'. The Indo-European root *walstands for 'cry', 'call', and 'speak'. Other related roots are Altaic *úlo, Uralic *wala,

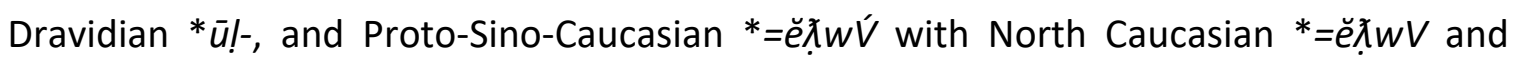
Sino-Tibetan * $/ \bar{o}$. The Borean root is in the historical languages extended to 'call', 'cry', and 'speak'. 


\subsubsection{Concepts with Eurasiac Roots and without Indo-European Representations}

a) PVTV with the conceptual meanings NAME, CALL and reflexion in $A-E-X-X-X$

Eurasiatic ${ }^{*} \dot{p} V t V$ and Afroasiatic $* p V d V d / H$ - refers to Borean PVTV with the meanings 'name' and 'call'. Eurasiatic * $\dot{p} V t V$ with the meaning 'name' is represented in Altaic *p'ét[e], Dravidian *pedj-[ar], and Chukchee-Kamchatkan Chukchi. *bityъ- for 'word' and 'speech'. The Borean root has reflexes in Afroasiatic * $p V d V d / H$ - and ProtoAfro-Asiatic * $p V d V d / H$ - with the meaning 'call' and the Semitic * $p d d$ - for 'shout' and 'call', Western Chadic *padVH- 'call' and 'speak', Central Chadic *papaḍ- for 'talk too much', and Dahalo (Sanye) pudud-for 'tell'. Proto-Sino-Caucasian *[q]wějV́ for 'swear' and 'be angry' is represented in North Caucasian *qwějV̆, Sino-Tibetan *Ḡ̄w, Yenisseian ${ }^{*} \chi V(P) j-$, and Burushaski * qhái. The Borean root is in the historical languages extended to 'shout', 'speak', 'talk too much', 'tell', 'swear', and 'be angry'.

b) MVHRV with the conceptual meanings SPEAK, SOUND and reflexion in A-E $-\mathrm{SC}-\mathrm{X}-$ $\mathrm{X}$

Eurasiatic *muyrV, Afroasiatic Semitic *?mr and ${ }^{*} \varsigma m r$, and Sino-Caucasian ${ }^{*} m V r H V$ refer to the Borean root MVHRV. Eurasiatic * murrV with the meaning 'cry' is related to Altaic *mura- 'shout' and 'cry'. Related are Uralic *mura, Kartvelian Georgian myer- 'sing', and Dravidian *mur-. Proto-Sino-Caucasian * $m V r H V$ has the meaning 'ask' and is related to Sino-Tibetan *maj and Burushaski *-mar-. The Borean root is in the historical languages extended to 'cry', 'shout', 'sing', and 'ask'.

c) HVPV with the conceptual meanings MOUTH, SPEAK and reflexion in A-E - X - AU AM

Eurasiatic * PVpV, Afroasiatic * ?ap-, Austric *bV?, and Amerind * pai refer to the Borean root HVPV. Eurasiatic *?VpV has the meanings 'mouth' and 'speak'. Related are 
Altaic *ip $\%$, Uralic *apta-, and Dravidian ${ }^{*} \bar{e} v$-. Proto-Afro-Asiatic * ?a-pay- has the meaning 'mouth'. Related are Semitic *pay- 'mouth' and *Pap- for 'mouth' and 'opening', Western Chadic *?ap- and *faw $(H)$ - for 'throw into the mouth', 'yawn', 'open', and 'mouth'. Related are Beḍauye (Beja) yaaf ('mouth'), Central Cushitic (Agaw) *?aff- ('mouth'), Saho-Afar *?af- ('mouth'), Low East Cushitic *?af- ('mouth'), High East Cushitic * Pafaw/P- ('mouth'), South Cushitic * Paf- ('mouth'), Dahalo (Sanye) afo 'lip' and 'mouth', and Omotic *?ap- 'mouth'. Proto-Austric *baha? has the meaning 'mouth'. Related are Proto-Austroasiatic *b? ${ }^{*} h$ and Proto-Austronesian *bahaq and *baqbaq. The Borean root is in the historical languages extended to 'throw into mouth', 'yawn', and 'open'.

d) RVWV with the conceptual meaning SHOUT and reflexion in $\mathrm{A}-\mathrm{E}-\mathrm{SC}-\mathrm{AU}-\mathrm{X}$

Eurasiatic Indo-European *rewa- 'shout' and 'roar', Afroasiatic ${ }^{*} r V P-/{ }^{*} r V w-$ 'speak', Sino-Caucasian * ${ }^{2} \not r H$ 'sound' and 'noise', and Austric PAA * $r V(w)$ for 'speak' and 'shout' refer to the Borean root RVWV. Proto-Afro-Asiatic *rVP-/*rVW- has the meaning 'speak'. Related are Semitic * $r V w V y$ - 'render other person's words', Egyptian $r$ ' for 'mouth', 'sentence', 'speech', 'language' in the Pyramide Texts, Western Chadic *rurufor 'shout' and Central Chadic *ray-for 'speak'. The Borean root is in the historical languages extended to 'render other person's words' and 'speak'.

e) JVNV (WVNV) with the conceptual meanings SPEAK, SAY, SOUND and reflexion in A $E-S C-X-A M$

The Eurasiatic *jVnV, Afroasiatic *yVn-for 'say', Sino-Caucasian *?wēni ( -u), and Amerind *wuni for 'cry' refer to the root JVNV. Eurasiatic *jVnV has the meanings 'speak' and 'sound'. Related are Altaic *iùjgula, Uralic *äne, and Dravidian *jan-. Related to the meanings 'weep' and 'howl' are Turkic *ijgala-, Mongolian *ujila-, and Japanese *ùnàr-. The Proto-Sino-Caucasian * $w_{w e ́ n} \dot{t}(\sim$ ?w-, $-u)$ has the meanings 'sound' and 'air movement'. Related are North Caucasian * Pwēnt $\left(\sim \varsigma_{w-,}-u\right)$ and Sino-Tibetan *?am. The Borean root is in the historical languages extended to 'weep', 'howl', and 'cry'. 


\subsection{Concepts without Eurasiatic Roots}

a) HVNV with the conceptual meaning SAY and reflexion in $\mathrm{X}-\mathrm{SC}-\mathrm{AU}-\mathrm{X}$

Sino-Caucasian * $=V \eta V$ and Austric PAN *bena with the meanings 'say' and 'tell' refer to the Borean root HVNV. Proto-Sino-Caucasian ${ }^{*}=V \eta V$ has the meaning 'speak' and is represented in Sino-Tibetan ${ }^{*} \eta a ̆ H ~ /{ }^{*} \eta a ̆ k$ and Yenisseian ${ }^{*} b-/{ }^{*}-\eta$-. The Borean root is in the historical languages extended to 'tell' and 'speak'.

b) HVLV with the conceptual meanings SAY, SPEAK and reflexion in $\mathrm{X}-\mathrm{X}-\mathrm{SC}-\mathrm{AU}-\mathrm{X}$

Sino-Caucasian *Hít $\breve{V}$ and Austric *IVw refer to the Borean root HVLV. Proto-SinoCaucasian *Hít $\breve{V}$ has the meaning 'say' and ist represented with North Caucasian *Hit_V $(\sim-\ddot{a}-)$ and Sino-Tibetan */ă. Yenisseian * PV(P)I- ( -r1-) and Burushaski */te- refer to the root. Proto-Austric * $I V w$ with the meanings 'speak' and 'tell' refers to it. The Borean root is in the specific root and historical languages extended to 'tell'.

c) TVPV with the conceptual meanings ASK, CALL and reflexion in $A-X-S C-X-A M$

Afroasiatic * $d V b$-, Sino-Caucasian * $d V P V$, Amerind *tempa, and African Bantu * dó(ó)mb- and *-támb- refer to the Borean root TVPV. Proto-Afro-Asiatic *dVb- has the meanings 'speak' and 'call'. To this root refer Semitic * $d V b V b$ - 'speak', Western Chadic $* d w a b$ - 'call', Low East Cushitic *deb- 'answer'. Proto-Sino-Caucasian *dVPV with the meanings 'hear' and 'answer' refers to Sino-Tibetan *tūp und Yenisseian *tVPV. The Borean root is in the historical languages extended to 'speak', 'call', 'answer', and 'hear'.

d) NVKV with the conceptual meanings CALL, SWEAR and reflexion in $A-X-S C-X-$ AM 
Afroasiatic *nug-, Sino-Caucasian * $\eta \breve{k} k w \breve{t}$, and Amerind *(a)nik refer to the Borean root NVKV. Proto-Afro-Asiatic *nug- has the meanings 'shout' and 'cry'. To this root refers Semitic *nug- 'cry', Egyptian ngg 'cry (of a goose)' in the Pyramide Texts, and East Chadic *nVg- 'shout'. To Proto-Sino-Caucasian * $\eta$ ěkwt́ with the meanings 'abuse' and 'swear' refer North Caucasian *nĕkw̆̆, Sino-Tibetan *niăkw', and Basque *naka-. The Borean root is in the historical languages extended to 'shout', 'cry', 'abuse', and 'swear'.

\section{Summary: On the Conceptualization of Speaking in Chains within Processes of} Convergence and Divergence

The above listed Borean roots are at least with two language families associated. The conceptualization of linguistic communication in its simplest form as 'speaking' or 'saying', but also more specific forms, can be assumed to have actually happened in the five areas, in which the Borean language family is supposed to exist.

Simple actions of speaking and complex actions of speaking can be distinguished. Simple actions of speaking, which have also representations in the Eurasiatic language family, are present in the following Borean roots:

$\begin{array}{lll}\text { WVTV } & A-E-X-X-X & \text { SPEAK } \\ \text { HVWV } & A-E-S C-X-X & \text { SPEAK } \\ \text { TVHV } & A-E-X-X-A M & \text { SAY } \\ \text { MVHRV } & A-E-S C-X-X & \text { SPEAK / SOUND } \\ \text { HVPV } & A-E-X-A U-A M & \text { MOUTH / SPEAK } \\ \text { JVNV (WVNV) } & A-E-S C-X-A M & \text { SPEAK / SAY / SOUND } \\ \text { WVKV } & A-E-S C-X-A M & \text { SAY / CALL }\end{array}$

The Eurasiatic language family is not represented in the following two Borean roots:

$\begin{array}{lll}\text { HVNV } & X-X-S C-A U-X & \text { SAY } \\ \text { HVLV } & X-X-S C-A U-X & \text { SAY, SPEAK }\end{array}$


Complex actions of speaking, which have also representations in the Eurasiatic language family, are present in the following Borean roots:

$\begin{array}{llll}\text { PVTV } & \text { A-E }-\mathrm{X}-\mathrm{X}-\mathrm{X} & \text { NAME, CALL } \\ \text { CVWV } & A-E-X-X-X & \text { SAY, SOUND } \\ \text { CVWV (2) } & A-E-X-X-X & \text { SPEAK, SHOUT } \\ \text { RVWV } & A-E-S C-A U-X & \text { SHOUT } \\ \text { WVLV } & A-E-S C-X-A M & \text { HOWL / CRY } \\ \text { KVRV } & A-E-S C-X-X & \text { CALL } \\ \text { KVWV (1) } & \text { A-E }- \text { SC }-X-X & \text { CALL } \\ \text { KVWV (2) } & \text { A-E }- \text { SC }-X-X & \text { CRY / SHOUT } \\ \text { MVLV } & \text { A-E }-X-X-A M & \text { SAY / PRAY }\end{array}$

The Eurasiatic language family is not represented in the following two Borean roots:

$\begin{array}{llc}\text { NVKV } & \text { A }-\mathrm{X}-\mathrm{SC}-\mathrm{X}-\mathrm{AM} & \text { CALL / SWEAR } \\ \text { TVPV } & \text { A }-\mathrm{X}-\mathrm{SC}-\mathrm{X}-\mathrm{AM} & \text { ASK / CALL }\end{array}$

In the reflexes we can observe semantic changes. From simple actions of speaking present in the following Borean roots we can find the following changes:

\begin{tabular}{|c|c|c|c|}
\hline Borean Root & Conceptual Meaning & & $\begin{array}{l}\text { Full Range of associated meanings in } \\
\text { Borean Root and Historical Languages }\end{array}$ \\
\hline HVWV & SPEAK & $>$ & 'speak' and extended meaning 'deny'. \\
\hline TVHV & SAY & $>$ & 'say' \\
\hline MVHRV & SPEAK / SOUND & $>$ & $\begin{array}{l}\text { 'speak' and 'sound' plus extended meanings } \\
\text { 'cry', 'shout', 'sing', and 'ask' }\end{array}$ \\
\hline HVPV & MOUTH / SPEAK & $>$ & $\begin{array}{l}\text { 'mouth' and 'speak' plus additional meanings } \\
\text { 'throw into mouth', 'yawn', and 'open' }\end{array}$ \\
\hline JVNV (WVNV) & SPEAK / SAY / SOUND & $>$ & $\begin{array}{l}\text { 'speak', 'say', 'sound' and additional meanings } \\
\text { 'weep', 'howl', and 'cry'. }\end{array}$ \\
\hline WVTV & SPEAK & $>$ & $\begin{array}{l}\text { 'speak' and the additional meanings 'read', 'recite', } \\
\text { 'sing', 'scold', 'order', 'utter', 'tell', and 'call' }\end{array}$ \\
\hline WVKV & SAY / CALL & $>$ & 'say' and 'call' pus additional meaning 'tell' \\
\hline
\end{tabular}




$\begin{array}{lll}\text { HVNV } & \text { SAY } & > \\ \text { HVLV } & \text { SaY, SPEAK and additional meanings 'tell' and 'speak' } & >\text { 'say' and 'speak' plus additional meaning 'tell' }\end{array}$

From complex actions of speaking present in the following Borean roots we find changes like:

Borean Root Conceptual Meaning

PVTV

CVWV

CVWV (2)

RVWV

WVLV

KVRV

KVWV (1)

KVWV (2)

MVLV

NVKV

TVPV
NAME, CALL

SAY, SOUND

SPEAK, SHOUT

SHOUT

HOWL / CRY

CALL

CALL

CRY / SHOUT

SAY / PRAY

CALL / SWEAR

ASK / CALL
Full Range of associated meanings in

Borean Root and Historical Languages

'say' and 'name' plus 'shout', 'speak', 'talk too much', 'tell', 'swear', and 'be angry'. 'say' and 'sound' plus additional meanings urge', 'advice', 'ask', and 'call' 'speak' and 'shout' plus additional meanings 'commend', 'affirm', 'become clear', 'praise', 'announce in a solemn way', 'promise', 'threaten', 'claim', 'speak', 'shout', 'cry', and 'tell' 'shout' plus additional meanings 'render other person's words' and 'speak' 'howl' and 'cry' plus extended meanings 'call', 'cry', and 'speak' 'call' plus additional meanings 'blow', 'smell', 'breathe', and 'ask' 'call' and additional meanings added 'call', 'invite', 'summon', 'consecrate', 'curse', 'roar', 'scream', and 'name' 'cry' and 'shout' and additional meanings 'whine' and 'howl' 'say' plus additional meanings 'ask', 'beg', 'vow', 'call', and 'indicate' 'call' and 'swear' and additional meanings 'shout', 'cry', 'abuse', and 'swear' 'ask' and 'call' and as additional meanings 'speak', 'call', 'answer', and 'hear' 
A consistency of the Borean roots in the reflexes of natural languages is clearly seen in the semantic field of all semantic meanings including the meanings of specific proto-languages and the historical languages. The idea of a Borean language family, which includes most of the world's languages, has been discussed and the here used Borean roots show with their "consonant - vowel - consonant - vowel" - pattern a simplification. But the basic phonetic structure of these roots, which is augmented in the historical languages of several language families, are a backup and argument for the existence of a commonly shared and similar phonetic pattern of words in the linguistic communication in different parts of the world.

The Borean roots examined show that within the areas of specific language families, especially in the Afroasiatic language family, Sino-Caucasian language family, and Eurasiatic language family, more than one Borean root for the simple genuine concepts of 'speak' and 'say" exist. So e.g. in all three language families the Borean roots $\operatorname{HVWV}(A-E-S C-X-X)$ for SPEAK, MVHRV $(A-E-S C-X-X)$ for SPEAK / SOUND, JVNV (WVNV) (A - E - SC - X - AM) for SPEAK / SAY / SOUND, and WVKV (A - E - SC $X$ - AM) for SAY / CALL exist. Looking at the fact that the existence of "proto-languages" and their data, which has connections across the boundaries of languages, allow us the claim that we should use concepts like 'chaining" or 'networking' for the obviously existing connection of linguistic communication at the age of the Borean language family; nevertheless, we must at the same time, when mentioning linguistic communication at the age of the Borean language family, also state that we cannot say more about the actual form and concepts of this linguistic communication. The idea and hypothesis that a Borean language family existed doesn't imply that a language existed at that time. When considering the Borean roots as the minimal shared group of phonetic components continuing in the majority of the to the Borean family associated languages, we can assume that the continuation of the phonetic components in the specific proto-languages of the language families and the related historical languages contains an addition of specific markers as characteristic of languages. As Gell-Mann, Peiros \& Starostin (2016) stated, the Borean language is supposed to have been active as a language in the time range between 25.000 to $18.000 \mathrm{BCE}$. 
The question of one origin of linguistic communication (monogenesis) or polygenesis at several places cannot be answered, even if we agree to the fact that a Borean language family exists; the Borean language family as a conceptual construct simply indicates that at a specific time in the prehistorical age (as above mentioned 25.000 to $18.000 \mathrm{BCE}$ ) the spoken linguistic communication entailed in wide regions of the world similar phonetic components, which were preserved at later states of human linguistic communication, where scientists use the term 'natural language'.

As McWhorter (2016: II) mentioned, it is known that "humans (...) travelled from southern Asia to New Guinea at least 50,000 years ago, with recent evidence suggesting as long as 75,000 years ago." This is an explanation for the relations between the Australic language family and other families. Jackendoff (2016) in How did Language Begin mentions that the only evidential finding regarding the faculty of speaking of the human species is the development of the vocal tract of the human species:

"About the only definitive evidence we have is the shape of the vocal tract (the mouth, tongue, and throat): Until anatomically modern humans, about 100,000 years ago, the shape of hominid vocal tracts didn't permit the modern range of speech sounds. But that doesn't mean that language necessarily began then. Earlier hominids could have had a sort of language that used a more restricted range of consonants and vowels, and the changes in the vocal tract may only have had the effect of making speech faster and more expressive."

McWhorter $(2016,1)$ in The Story of Human Language mentioned that "despite influential speculations, it is unclear whether Neanderthals could speak in the same manner as Homo sapiens, and theories that language emerged as the result of a single gene mutation about 30,000 years ago are increasingly controversial as well." McWhorter $(2016$, I) noticed that "according to paleontological and genetic evidence, many have argued that it was only about 50,000 years ago that there was an explosion in sophistication among Homo sapiens, resulting in finer tools, cave art, the bow, tents, and huts." McWhorter $(2016, \mathrm{I})$ concluded that "it is highly likely that human language emerged in Africa, with the emergence of either Homo sapiens or possibly earlier species of Homo. Supporting this is the fact that there is a gene called FOXP2 that is 
connected with the ability to use language, and it traces back 100,000 years, long before the 50,000-year mark that "Big Bang" theorists designate as the birth of language."

Considering 'language' or any kind of 'linguistic communication' to be an arbitrary and symbolic communication has an aspect - the arbitrariness - , which needs to be re-considered in the light of hypothetical findings like the Borean language or any protolanguage, which is the results of an inductive process of several individual observations at the level of the historical languages followed by the extraction of the smallest 'minimal' phonetic representation for all languages, which lead to the conclusion of a hypothetical language family in both cases of the proto-languages and the Borean language family. The inductiveness of the process with the observed material of the historical languages and its abstraction make the process applied here rather empirical than theoretical; a theoretical and hypothetical constructed 'proto-language' or 'Borean language' is the result from observations in an area and time, where no historical document can be found as proving evidence. Of course, we can ask and criticize the actual format of the hypothetical type of 'linguistic communication', which is employed to describe the similarities of historical languages. Implying that linguistic communication' prior to the emergence of historical languages was 'linguistic communication' like we use to separate today historical languages and dialects as spoken variations is an irritating and probably false conclusion as a speculative assumption of analogue patters between pre-historical 'linguistic communication' and historical languages.

On the one hand, it is likely to assume that in pre-historical time like in historical languages the use of language was closely associated with the identification of the group of its speakers in contrast to the actual other forms of linguistic communication. But on the other hand, the presence of the similarities of lexemes in the hypothetical languages allow mentioning that the principle of convergence, when it came to contact between humans able to communicate, must have been stronger than the principle of divergence among humans able to use any means of 'linguistic communication'. Whereas 'convergence' is a necessary means to maintain the communicative function of language and similarity is one of its features, the complementary aspect of the dichotomy, divergence, is a driving force for the non-similarity ('otherness') between 
languages or any type of 'linguistic communication'. 'Convergence' allows languages or any type of 'linguistic communication' to be shared and systematic, while 'divergence' is a process of differentiation of languages or any type of 'linguistic communication'. The here presented phenomena documented in chains of phonetic sets existing across language families can be seen as results from processes of convergence present at an early stage of human communication, which at a later stage experienced differentiation processes of 'divergence'.

\section{References}

DELLERT, Johannes \& Armin BUCH (2015) “Using Computational Criteria to Extract Large Swadesh Lists for Lexicostatistics", EVOLAEMP Project. Language Evolution. The Empirical Turn. Philosophische Fakultät. Seminar für Sprachwissenschaft. University of Tübingen. June 23, 2016 <http://www.sfs.uni-tuebingen.de/ jdellert/talks/jdellert-abuch-2015-10-28.pdf>.

E-LINGUISTICS DATABASE. ELINGUISTICS (2016) Web, June 23, 2016 <http://www.elinguistics.net/>.

Gell-ManN, Murray; Ilia Peiros \& George Starostin (2016) "Evolution of Human Languages. Testing the "Borean" Hypothesis", Evolution of Human Languages. An International Project on the Linguistic Prehistory of Humanity coordinated by the Santa Fe Institute. Santa Fe Institute, June 23, 2016 <http://ehl.santafe.edu/borean.htm>.

Global Lexicostatistical Database (2016) Center For Comparative Studies. Russian State University for the Humanities, Moscow. Evolution of Human Languages Program. Santa Fe Institute, New Mexico. The Tower of Babel, Web, 23, June 2016 <http://starling.rinet.ru/new100/main.htm>.

JACKENDOFF, Ray (2016) “How did Language Begin?" Linguistic Society of America, Web, June 23, 2016 <http://www.linguisticsociety.org/sites/default/files/LanguageBegin.pdf>.

MCWHORTER, John (2016) The Story of Human Language. Part I-III. Chantilly, VA: The Teaching Company, 2004. École des Mines de Saint-Étienne, Web, June 23, 2016. <http://www.emse.fr/ bsimon/documents\%20p\%E9dagogiques/p\%E9dagogie/The\%20st ory\%20of\%20language/TTC\%20-\%20Story\%20of\%20Human\%20Language\%20\%20John\%20McWhorter/Story\%20of\%20Human\%20Language\%20\%20Course\%20Guide.pdf>. 
Dialectologia 23 (2019), 115-149.

ISSN: 2013-2247

POKORNY'S LIST (2016) in Indo-European Lexicon. PIE Etyma and IE Reflexes. Jonathan Slocum (ed.), Linguistics Research Center. College of Liberal Arts at the University of Texas at Austin, Web. June 23, 2016.

<http://www.utexas.edu/cola/centers/Irc/ielex/PokornyMaster-X.html>.

Starling etymological Databases. The Tower of Babel Project (2016) Sergey Starostin (ed.), Starling, Web, June 23, $2016<$ http://starling.rinet.ru/>.

StAROStIN, George (2010) "Preliminary Lexicostatistics as a Basis for Language Classification: A New Approach." First published in Journal of Language Relationship, 3, 79-116, The Tower of Babel, June 23, 2016 <http://starling.rinet.ru/new100/Lexicostatistics.htm>. 